\section{Raising Research Consciousness the Fa'aSamoa Way}

\author{
ANNE MARIE TUPUOLA
}

\section{Abstract:}

For too long non-Western indigenous researchers have been limited in their research because of the "scholarship" attached to ethnocentric and culturally insensitive methodological frameworks. This paper highlights the very rich experiences of the author's alternative methodology in the Samoan context, and argues the need for the world of Western academia to acknowledge "other" cultures' perception of scholarship and knowledge. It focuses on the necessity for both non-indigenous and indigenous researchers to take into consideration the culture of participants, and to incorporate their culture into the methodological framework and written text.

1 993 was an exciting educational year, particularly for indigenous researchers. Educational conferences worldwide showed interest in the International Year of the World's Indigenous Peoples by implementing themes which raise consciousness among academics about other cultural world views. This article highlights issues concerning research on Samoan peoples and emphasises the necessity for educationalists to minimise exploitation within cross-cultural research, by designing and implementing theoretical and methodological frameworks culturally sensitive to other cultures' world views and communication styles. In the following presentation I shall be discussing my 1993 Masters thesis, "Critical Analysis of Adolescent Development - A Samoan Woman's Perspective", with the hope of showing the limitations of applying Western theories and

\section{Anne Marie Tupuola}

methodologies to a non Western culture such as fa'aSamoa. Furthermore, I shall be highlighting the complexities involved in designing and creating unorthodox theses because of the conflicts between what the Western world of academia and Samoan people perceive as "scholarship".

\section{Why a Samoan Perspective of Adolescence?}

The concept of adolescence, although a recent phenomenon, cannot be used as a general term for referring to the period between childhood and adulthood for all cultures. One only needs to read through literature to see how some researchers conveniently use the term "Samoan adolescence" without first defining adolescence within a Samoan context. Do young Samoansidentify themselves as adolescents? Are young Samoans acknowledged by their culture as adolescents?

These issues were raised after reading Margaret Mead's ethnography "Coming of Age in Samoa". Although there has been continuous debate about this research by both Samoan and non Samoan people, no research that I am aware of looks at the following issues: How did Mead define Samoan adolescence? Did the young women in Samoa identify themselves as adolescents? How appropriate was it for Mead to research adolescence in a non Western culture?

Already sceptical of monocultural theoretical and methodological frameworks within the cross-cultural arena, I decided to re-analyse Mead's interpretation of Samoan adolescent girls. Aware of criticism made about my approach of using Margaret Mead's research (e.g., the time factor, dated work on adolescence), I need to remind academics that Mead's research is still popular within contemporary human development and anthropology textbooks. As a New Zealand under-graduate and post-graduate student it was frustrating to have Margaret Mead's research as a major reference/source (in many instances the only one) on Samoan adolescent girls, particularly when I, like other Samoans, found the issues raised in her research insulting and 
offensive. I also need to emphasise that, even though her study was in the 1920s, generalisations in the 1990s by some non Samoans still seem to be based on Mead's findings on the human development process of Samoan girls (particularly regarding sexuality). The following comments by women in my research illustrate their concerns on this issue:

I remember sitting in one of my human development classes and we got on to the subject adolescence and there was Mead's study in our textbook claiming that Samoans experienced an undisturbed adolescence, contrary to theorists of that time who believed adolescence was a time of storm and stress. And, like 'cause people in my tutorial knew I was Samoan they all assumed that I went through a calm and cool childhood and upbringing and that I knew what adolescence was. I sat there dumbfounded, listening to how people interpreted my developmental process. They assumed that Mead's study was relevant to Samoan women in the 1990s 'cause there wasn't an updated version or realistic description of young Samoan girls in the textbook. What they didn't know was that I didn't understand adolescence and I found Mead's perception of the Samoan girl really foreign to me.

I mean, when I attended classes that discussed this book I left the class really intimidated and I felt ostracised from the human race because of it. I mean, here I was sitting amongst people discussing and laughing at my culture. I'll never forget the day when the guy next to me said jokingly, "boy, I wouldn't go there for a honeymoon, it'll be too tempting with all those sex-hungry birds..."

With all these issues in mind, it was imperative to examine and critically analyse adolescence during Mead's study as it was her research which initially investigated "Samoan adolescence". The focal points of my research were firstly to discuss the definitions of adolescence popular in the early 20th century, including Mead's ethnography, to examine whether Samoan girls may have experienced adolescence in the 1920s. Seventy years on from Mead's research we then asked ourselves if Samoan girls identify themselves as "Samoan adolescents" today.

\section{Why the Need for Fa'aSamoa Methodologies?}

There appears to be a general feeling among the Western world of academia that methodologies have changed vastly since the period of Mead's research. However, there is a need to ask ourselves if there has been any real significant change in our attitudes toward alternative cultural methodologies. Does today's academic environment merely appear empathetic toward other cultural methods within a theoretical context but reluctant to practise and accept these methodologies because they are perceived to be unscholarly? Reflecting upon my own research, I need to emphasise that the perception of scholarship within the present academic structure appears ethnocentric in nature because, even though I presented a thesis which revolved around fa'aSamoa values, the criteria placed for "scholarly work" were predominantly palagi (European) orientated. For some academics "texts which include both the subjective and objective aspects of knowledge are often considered unphilosophical" (Hamilton \& Tomm, 1988: xvii), "trivial, undisciplined and inferior..." (Dansereau, 1988: 4) even though they may be culturally appropriate to the communication style of some non Western peoples and cultures. For future non Western researchers this may lead to cultural conflict particularly, at the thesis level, as illustrated by Helen Page. The context and expression of her informants' words and experiences seemed to be ignored because of the ethnocentric and eurocentric criteria held for academic and scholarly writing.

I discovered, for example, that my dissertation committee wanted my dialogic data to be sanitized, and thus my rich rendering of the southern dialect of African-American speech had to be "cleaned up" by eliminating the so-called noise... The committee wanted only information which seemed to directly refer to some objective thing, rather than information about something that was subjectively felt... (Page, 1988, pp. 163-164). 
Within the last decade there appears to have been progress by some academics toward minimising exploitation in the research process. However, we need to remind ourselves of how susceptible some researchers (indigenous researchers included) may be to the trappings of Western thought (Etter-Lewis, 1991). What are these trappings? Some researchers' theoretical and ideological frameworks may be culturally insensitive because their informants' experiences continue to be perceived within the researchers' own world view. Achola Pala's analysis of this problem can be seen in the following example where cultural issues of the informants appear secondary to the interests of the researcher.

I have visited villages where, at a time when the village women are asking for better health facilities and lower mortality rates they are presented with questionnaires on family planning. In some instances when women would like to have piped water in the village, they may be at the same time faced with a researcher interested in investigating power and powerlessness in the household... (Pala, 1982, cited in Carby, p. 227).

In the written text some researchers conveniently slot the voices of the "other" culture into textual spaces pleasing to them (Tedlock, 1987) and paraphrase the truths of non Western participants within a context meaningful to the researcher and his or her intended audience and theoretical framework. Ethnography which enables the researcher to control both the research process and written text may be exploitative and culturally insensitive because the words of the informants may merely appear in the text to reinforce the argument of the researcher. Rather than allowing the informants' words to stand on their own "... the people studied are treated as garnishes and condiments, tasty only in relation to the main course..." (Richardson, 1989, cited in Lather, 1989, p. 22).

To avoid such tokenism, research frameworks on Samoan people must prioritise their "holistic" perception of knowledge and scholarship, oral communication style and protocol of consensus and respect. For too long we have had to express our thoughts within a palagi framework. The time has come for Samoan research to be processed and written within a Samoan context.

\section{Designing a Culturally Sensitive Methodology}

My Masters research worked toward minimising exploitation and ongoing ethnocentricism by prioritising the cultural and gender needs of both researcher and participants. The following discussion will briefly describe the approach I took in designing and enacting an alternative, culturally sensitive methodological and literary structure. I shall include feedback from some participants so that researchers may understand the necessity to work within a consensus framework in Samoan research.

At the initial stages of my research I was adamant in my determination to design a methodology that revolved around fa'aSamoa values. Research in the past on Samoans seemed to dangerously imply that Samoans were a homogeneous race. Aware of the diversity among my people and culture I felt it was necessary to invite other Samoan women to join me in analysing the concept "adolescence". Additionally, it was important for me to exercise the research process and the written text within frameworks which would sustain an egalitarian relationship with all participants both in fieldwork and during the final write up of the text.

Selecting the participants was done by collaborating with several young Samoan women. It was they who suggested that I should not be involved in the selection process and that they would inform their friends and/or other Samoan women about my research and have them spread the word to others. Subsequently, this "snowball" approach encouraged 13 Samoan women (including myself) from two different cities in New Zealand between the ages of 16 and 29 to participate. 
Wanting to acknowledge the oral and collective communication styles of these women, I created a format that distanced from the individualistic interview and questionnaire with group discussions. This was done by providing participants with prepared pages of quotations, paragraphs and extracts for them to reflect upon. The main criterion for choosing the quotations was to provide all participants with a wide range of definitions of adolescent development popular within Mead's era and of literature that examined Samoan culture and behaviour within a cross-cultural context. Hoping to minimise possible bias that may have been involved in the selection process of these quotations, I felt it was appropriate to encourage participants to use these extracts and/or quotes in a fashion that suited them. Members had every opportunity to choose the quotations they wished to discuss, interpret and/or criticise without my interference. All participants were to use these quotations only as starting points for conversation or for reminiscing over their own experiences or human development process. In this respect the opportunity of directing the outcome of this research became limited even though I initially chose the different quotations and extracts. The following comments (which were selected by participants to be included in my thesis) illustrate these women's reaction and response to this procedure and toward the researcher choosing the quotations.

These quotes were valuable and, like we just looked at them and thought, "Oh yeah, maybe or perhaps." They just helped but it wasn't a hindrance or anything.

I thought it was really good how Anne-Marie chose the quotes but then at the same time we choose the quotes to talk about because it showed that there was a balance between her role as a researcher and our role as participants. It was definitely a novel idea which worked really well.

We wouldn't have bothered doing the research if you told us we had to choose the questions, because, like we'd have to go to the library, go through books!! We'll go, "Oh look, sorry we don't have time," I know I wouldn't have bothered.
Culturally sensitive to fa'aSamoa protocol and etiquette of fa' aaloalo (respect) and consensus, I understood how imperative it was for the researcher to consult all participants on the research topic, the initial methodological structure and the framework of the written text before, during and after this research. Did they understand the research topic? How did they feel about the methodology? Were there any issues they wished to raise? Through informal introductory gatherings with the women before the actual fieldwork various suggestions were made by them. Confidentiality was considered a very important issue. Rather than having two groups (one from each city) they chose to be within smaller groups and with members they felt comfortable with. Consequently four distinctive groups were formed. Members who had difficulty participating orally were given the opportunity to express their viewpoints on paper. Transcriptions from each meeting were to be made available to all participants involved so that communication and the exchange of ideas between all the groups would be possible. All the women approved my proposal for them to check their own transcriptions and the way their words were placed in the written text to ensure that the analysis and conclusions of this research illuminated their truths. These introductory gatherings therefore enabled the researcher to clarify and test the feasibility of the proposed methodology. It was also an opportunity to assess the participants' response toward a research process that would emphasise dialogue, self-reflexivity, flexibility, collaboration and consensus. I need to emphasise that it is ironic that research and literature within the social sciences have only come to grips with these features within the last decade as they have always been intricate aspects of the Samoan culture. It would be ethnocentric for academics to assume that this research method chose to focus on collaboration, consensus and self-reflexivity because they were in line with the intellectual climate of the late 20th century or because dialogue was a "fashionable metaphor" (Marcus \& Fischer, 1986). Rather, this research prioritised elements which reflected and acknowledged the communication style of Samoan people and the nature of fa'aSamoa. 


\section{Writing the Text Within a Samoan Context}

Although much literature has been written about Samoan people, very few (if any) seem to present the truths of Samoan people within a culturally sensitive textual framework. To avoid such tokenism, Samoan peoples' experiences need to be expressed and written within a context that complements the oral and dialogic nature of our communication style. In the past Samoans have been at a disadvantage because literature, although written about us, appears collated and written in a form that "appeals only to a small, educated elite...firmly confined to the universities" (Watt, 1985: 286). Many of the theories and models used within the social sciences to analyse Polynesian societies have been loaded with Western language and structures to describe our behaviour (Ralston, 1988). Samoan people have been labelled variously from "savages" to "sexually permissive" to "puritanical", all of which carry with them negative judgements of our life styles. When Samoans have been studied, some have not had the power to choose what is to be said, how it is to be expressed and how their words should be written because that control seems to be exercised by the "all-knowing author"

With these issues in mind, it was important to design an emancipatory text which allowed participants to work alongside the researcher throughout the writing process of this research. Working within the objectives set at our introductory gatherings, contributors checked the context in which their comments were placed and ensured that the analysis in the text complemented their overall viewpoints. Additionally, feedback by the women that appeared in the text had been examined by them to ensure there was a fair representation of their opinions on different matters. Issues that we reached consensus upon were included in the conclusion and reflection sections in the thesis. This text did not paraphrase the participants' voices and therefore included unedited responses so that their truths could not be distorted nor misinterpreted by the author. Overall my thesis created an illusionary room where all participants (academics and researcher included) were thought to be conversing with each other, illuminating the significance of the oral narration that took place. It also prioritised the inclusion of comments in the Samoan language and allowed Samoan women to analyse and discuss our own situations within our own literary context. More importantly, rather than my being the "all-knowing author", all the participants were made accountable and this research emphasised that the researcher was not necessarily more knowledgeable but that both researcher and participant in partnership created knowledge. The following comment illustrates a member's viewpoint on this exercise:

I can remember asking Anne-Marie if she ever thought of writing another section and I honestly expected her to forget about it and let it drift but then she wrote to me a few weeks later saying that she would and asked me if there was anything in particular I wanted discussed. And like, yeah, I really felt like a participator in this research and I'm glad she listened to my needs.

\section{Raising Consciousness of Fa' aSamoa Research Issues}

After examining adolescent development within Mead's era and then reflecting upon our own experiences as Samoan women in the 1990s it was evident that within a Samoan context "adolescence" was not a term used to identify young Samoan women. Although we were not able to speak on behalf of the Samoan girls of the 1920s we nevertheless were able to examine how fa' aSamoa affected our present human development process. Aware of scepticism of this research because of the time factor, many of the participants discussed fa'aSamoa issues with their extended families and elders to enable us to at least sense some differences (if any) in the expectations fa'aSamoa held for young women then and now. From this study it appears that even though the Samoan culture seems to have progressed from 70 years ago, the traditional values impinged upon young Samoan women have not changed considerably. Opportunities to mature sexually, to engage in heterosexual relationships and to seek 
independence are still not encouraged in some Samoan girls. Consequently the more popular theories of adolescence found in some human development courses which emphasised these qualities were foreign to many of the participants as shown in the following comments:

In Samoa to have a boyfriend? I don't think so. It's the most scariest thing to do is to have a boyfriend, eh? It's you want, you may want to have a boyfriend in Samoa but you will just go through hell just trying to hide the thing.

I know a young Samoan girl who recently arrived from Samoa who fell pregnant at the age of fourteen. What I found hard to understand was that she was still not clear how it happened and was not aware of the consequences. Like she told me that she didn't even know she was pregnant until she felt something kicking inside and, like she was five or six months pregnant. When her period stopped she thought nothing of it and assumed that she was putting on weight. But like when she had that child she did not understand the responsibility that came with it and to her it was like having a moveable doll. So you can't assume that once your body is reproductively mature that you will understand more about sex because, for her, being Samoan and being brought up in a very fa'aSamoa environment, no one ever told her about sex. So it's very sad.

Independence seems so important for Western societies, but for us, nah, 'cause individualism is not encouraged nor is it important. I'd rather be with my family than being all alone, even if I get old...

Realising how other cultures may identify with some of the controversial issues raised in my research, we all need to remind ourselves that although cultures may share commonalities it seems ethnocentric to generalise that women of other cultures would share the same effects and interpretations of their own experiences with their own culture. Every culture is different and it is therefore imperative for "others" to read or examine our culture only within our world view. Therefore some academics may be culturally insensitive when they compare our experiences with other cultures without allowing our stories and truths to stand on their own first.

Although I perceive my research as a step toward a culturally sensitive and non-exploitative research of Samoan women, there were restrictions placed by the world of academia on how a thesis should be structured and what seemed to be scholarly acceptable. I personally felt unable to produce a research that fully complemented fa'aSamoa values because I still had to fulfil criteria that were individualistic in nature. While this research exercised collaboration and consensus between the researcher and the contributors both in fieldwork and in structuring the final text, the focal point of examination appears to be toward the knowledge, analysis and interpretation of the researcher. While the focus of this research was on a Samoan perspective, limitations were inevitable in that our truths could not stand on their own because a thesis should include "academic" insight as well. Writing a text sensitive to the oral and communal nature of our learning and communication styles had further complications because a thesis should include analytical prose, not subjective and emotional narrations of our experiences. Such limitations proved frustrating for me because even though this research was implemented and facilitated by a Samoan researcher I seemed trapped between the ethnocentric and eurocentric expectations of scholarship and knowledge and my culture's perception of scholarly and culturally appropriate methodologies and writing of Samoan issues. There needs to be some consciousness raising among the academic environment on the necessity for "other" cultures to tell their story within appropriate structures and to recognise that methodological frameworks in this era need to be unique because every research situation is different and every culture has different needs.

There is not merely one appropriate methodology, nor one type of research project, that all scholars should rush to duplicate. 
No blanket prescription will help us, we need, rather, to engage in self-critical examination of our practices and to go on to develop a range of models from which to select our procedures according to the needs of specific, and often unique, research situations (Gluck \& Patai, 1991, p. 222).

\section{My Concluding Thoughts}

Has there been any actual change of attitude toward alternative cultural research frameworks by the world of academia? I have found it encouraging that some academics have been receptive to this form of research but there is still a need for more academics to distance themselves from their own world views when they read and analyse this research to fully grasp and appreciate our truths. It is fair to say that some Western academics are quick to criticise innovative cultural research yet in some instances miss the point because they continue to perceive other cultures through Western thoughts, concepts and structures. I am therefore sceptical of "significant" change in the academic environment toward alternative cultural research methodologies because as a Samoan researcher I had to ask, Whose cultural values must I choose in order to be successful in the academic world? Am I to research my culture and people within a culturally sensitive manner only then to contradict my fa' aSamoa values by having to restructure our stories within a culturally conflicting conventional Western academic framework? It seems for too long I, like other non Western researchers and peoples, have had to adopt and adapt to foreign concepts, structures and research frameworks. The time has come for the Western world of academia to change their way of thinking to accommodate Samoan and other non Western research.

In making this contention, I am well aware that some quarters of the academic world will demand proof and corroborative evidence. I have none, other than the fact that I am a Samoan (Wendt, 1984, p. 96).

\section{References}

Carby, H. V. "White Women Listen! Black Feminism and the Boundaries of Sisterhood", in Contemporary Cultural Studies, The Empire Strikes Back: Race and Racism in 70s Britain, UK: Hutchinson \& Co. Ltd, 1992.

Dansereau, E. "Strategies in Literary Criticism", in Hamilton, George and Tomm, Winnifred (eds) Gender Bias in Scholarship: The Pervasive Prejudice, Canada: Wilfred Laurier University Press, 1988.

Etter-Lewis, C. “Black Women's Life Stories: Reclaiming Self in Narrative Texts", in Gluck, Sherna Berger and Patai, Daphne (eds) Women's Words: The Feminist Practice of Oral History, UK: Routledge, Chapman \& Hall Inc, 1991.

Gluck, S. B. \& Patai, D. (eds) Women's Words: The Feminist Practice of Oral History, UK: Routledge, Chapman \& Hall Inc, 1991.

Hamilton, C. \& Tomm, W. (eds) Gender In Scholarship: The Pervasive Prejudice, Canada: Wilfred Laurier University Press, 1988.

Lather, P. Deconstruction/Deconstructive Inquiry: The Politics of Knowing and Being Known. Paper presented at the American Educational Research Association Annual Conference, San Francisco, California, U.S.A., 1989.

Marcus, G. E. \& Fischer, M. J. From Anthropology As Cultural Critique: An Experimental Moment in the Human Sciences, USA: University of Chicago Press, 1986.

Mead, Margaret Coming of Age in Samoa: A Study of Adolescence and Sex in Primitive Society, UK: Penguin, 1943.

Ralston, C. "Polyandry, 'Pollution', 'Prostitution': The Problems of Eurocentricism and Androcentricism in Polynesian Studies", in Caine, Barbara et al. (eds) Crossing Boundaries: Feminisms and the Critique of Knowledge, Australia: Allen \& Unwin, 1988.

Tedlock, D. "Questions Concerning Dialogical Anthropology” , Journal of anthropological Research, 43, 1987, pp. 325-337. 
Tupuola, A. M. \& Bird, L. "Coming of Age in the Academy", Paper presented at the Post-Colonial Formations Conference, Griffith University Institute for Cultural Policy Studies, Brisbane, AUST, 1993.

Tupuola, A. M. “Is There Room for Non Exploitative Methodology in the Academic World?" Paper presented at the World Indigenous Peoples Conference: Education, Wollongong, NSW, AUST, 1993.

Tupuola, A. M. "Critical Analysis of Adolescent Development - A Samoan Women's Perspective", Unpublished M.A. thesis, Education Department, Victoria University of Wellington, 1993.

Watt, J. "Literature and Liberation: Black Consciousness in Recent South African Writing", in Ethnic and Racial Studies 8 (2), 1985, pp. 277-291.

Wendt, F. Review of Freeman's Book, Pacific Studies 7(2), 1984, pp. 92-99.

\section{The author}

Anne-Marie Tupuola is a post-graduate student in the Education Department of Victoria University. Her interests are in the cultural perspectives of adolescent development and in culturally sensitive research frameworks. 